\section{ОСОБЕННОСТИ ПЛАНИРОВАНИЯ СОЦИАЛЬНОЙ ПРОГРАММЫ АКТИВИЗАЦИИ МОЛОДЕЖИ}

\section{Аннотация}

В статье описывается возможный механизм планирования социальной программы активизации молодежи, разработанный на основе научных принципов социального программирования с учетом эмпирических результатов авторского исследования по совершенствованию механизма управления молодежными программами.

\section{Ключевые слова:}

молодежь, социальная программа, этап планирования, ресурсное обеспечение программы, соци альная диагностика проблемы, направления реализации социальной активности.

\section{THE FEATURES OF DESIGNING OF THE SOCIAL PROGRAM ENGAGING YOUTH AS ACTIVE CITIZENS}

Summary:

The paper describes a possible mechanism of designing of the social program focused on making the youth more active developed on the basis of the scientific principles of social programming taking into account the empirical results of the author's original research on the improvement of the mechanism of youth programs management.

Keywords:

youth, social program, planning phase, resource support of program, social diagnostics of problems, areas of social fulfillment.

Активизация молодежи является значимой задачей при реализации государственных социальных программ. Анализ текстов действующих в настоящее время госпрограмм по молодежной политике 30 регионов России (Краснодарского края, Липецкой области, Удмуртской Республики, Республики Хакасия, Самарской области и др.) показал, что более 60 \% из них включают мероприятия, направленные на увеличение охвата молодежи соответствующими мероприятиями, тем самым подчеркивается необходимость активизации молодежи. В целях оптимизации положений проектов целесообразно обратиться к механизму социального программирования.

Первым и наиболее значимым в реализации социальной программы является этап планирования (подготовки), поскольку от детальности и проработанности плана зависит эффективность программы в целом [1]. Данная стадия может включать разный набор и порядок действий. Так, Ж.Т. Тощенко считает необходимым производить диагностику социальных проблем; отбирать проблемы, подлежащие решению программным способом; осуществлять целеполагание; определять ресурсы, которыми располагает субъект управления; устанавливать средства, при помощи которых можно достичь цели [2, с. 10-13].

Финские ученые Т. Саати и К. Керне в свою очередь на этапе планирования добавляют определение показателей социальной программы [3, с. 87]. Н.Н. Богдан и Т.В. Климова устанавливают следующую последовательность действий при разработке программы: конкретизация проблемы, формирование концепции; сбор и анализ данных для выявления масштабов конкретных социальных потребностей; формирование содержания программы, основных критериев и показателей достижения результата; планирование мероприятий и расчет ресурсов [4, с. 180$]$.

Обобщая изложенные подходы к планированию социальных программ активизации молодежи, подчеркнем, что на данном этапе необходимо произвести диагностику социальной проблемы на основе социологических исследований, определить цель и задачи, ресурсы и средства их достижения, а также установить ключевые показатели и перспективы их реализации.

Диагностика социальной проблемы тесно связана с идентификацией субъекта и объекта управления. Первый в молодежной политике может быть представлен двумя типами: государственными ведомствами, отвечающими за реализацию госполитики и программ; молодежными общественными организациями. Объектом управления в свою очередь являются как молодежь в целом, так и отдельные социальные общности и группы в молодежной среде.

При определении уровня активности молодежи в качестве социальной проблемы необходимо учитывать позиции как молодых людей (их уровень социальной активности), так и субъекта управления, осуществляющего молодежную политику. Мы провели социологическое исследование среди молодых людей Курской области (16-30 лет) с общим объемом выборки 600 человек. Также проведен экспертный опрос среди специалистов в сфере молодежной политики - 60 человек. 
Результаты исследований и диагностика социальной проблемы реализации программы активизации молодежи позволили сформулировать основную цель программы, определить задачи и средства для достижения поставленных целей по социально значимым направлениям. В качестве цели рассматриваемой социальной программы можно назвать обеспечение социального становления и развития личности молодых граждан, наиболее полного проявления их социальной активности с учетом личностных качеств.

В таблице 1 приведены выявленные в результате диагностики социальной проблемы основные задачи и средства достижения поставленной цели. Среди средств, способствующих достижению поставленной в программе цели, по мнению молодых людей, наиболее действенным является «подготовка кадров по работе с молодежью», для субъектов управления программами - «увеличение фринансирования» и «поддержка добровольческих инициатив молодых людей».

Таблица 1 - Основные задачи социальных программ активизации молодежи

\begin{tabular}{|c|c|c|}
\hline Задача & Направление & Средства \\
\hline \multirow{3}{*}{$\begin{array}{l}\text { Расширение участия } \\
\text { молодежи как объекта } \\
\text { управления }\end{array}$} & Социально-трудовое & Подготовка кадров по работе с молодежью \\
\hline & \multirow[t]{2}{*}{ Общественно-политическое } & Подготовка кадров по работе с молодежью \\
\hline & & $\begin{array}{l}\text { Поддержка добровольческих инициатив } \\
\text { молодых людей }\end{array}$ \\
\hline \multirow{5}{*}{$\begin{array}{l}\text { Оптимизация активности } \\
\text { субъекта управления }\end{array}$} & \multirow[t]{2}{*}{ Культурно-досуговое } & Увеличение финансирования \\
\hline & & $\begin{array}{l}\text { Поддержка добровольческих инициатив } \\
\text { молодых людей }\end{array}$ \\
\hline & \multirow{3}{*}{$\begin{array}{l}\text { Учебно-познавательное } и \\
\text { научное }\end{array}$} & Регулирование нормативно-правовой базы \\
\hline & & Подготовка кадров по работе с молодежью \\
\hline & & Увеличение фринансирования \\
\hline \multirow{4}{*}{$\begin{array}{l}\text { Поддержка интереса } \\
\text { и уровня активности } \\
\text { объекта и субъекта }\end{array}$} & \multirow[t]{3}{*}{ Спортивно-оздоровительное } & Подготовка кадров по работе с молодежью \\
\hline & & Увеличение финнансирования \\
\hline & & $\begin{array}{l}\text { Поддержка добровольческих инициатив } \\
\text { молодых людей }\end{array}$ \\
\hline & $\begin{array}{l}\text { Инфрормационно-коммуника- } \\
\text { тивное }\end{array}$ & Подготовка кадров по работе с молодежью \\
\hline
\end{tabular}

Выделенные средства могут также трактоваться как возможные ресурсы обеспечения социальных программ, что подтверждается трудами Н.С. Данакина. При освещении ресурсного обеспечения программ он учитывает такие ресурсы, как кадровые, организационные, научно-методические, фринансовые, социальные, нормативно-правовые, информационные, технологические, аналитические [5, с. 54].

В ходе планирования социальной программы также следует определить ключевые показатели, по которым будет оцениваться успешность ее реализации. Для программы активизации молодежи таким фактором является количество лиц, вовлеченных в активное взаимодействие с государством, его структурами. Для достижения наилучших результатов необходимо учитывать выявленные на этапе диагностики значимые фракторы-дезорганизаторы (информационный, организационный).

В таблице 2 приведены возможные фракторы увеличения численности молодых людей, вовлеченных в процесс реализации программ, за счет устранения фракторов-дезорганизаторов. Выделенные показатели играют главную роль в устранении доли неучастия в программах. Плановые значения основаны на результатах социологического исследования. Так, наиболее важный фактор - информационный: для 27 \% молодых людей он является единственным, в результате наибольший эффект от его устранения - увеличение численности участников программ до $27 \%$. За счет организационного фрактора возможно возрастание их числа в результате кумулятивного эфффекта, т. е. этот параметр совместно с информационным способен максимально повысить численность людей, привлеченных к реализации молодежной политики, до 38 \%.

Таблица 2 - Факторы увеличения социальной активности молодежи, \%

\begin{tabular}{|c|c|c|c|}
\hline Фактор & Минимальное значение & Плановое значение & Максимальное значение \\
\hline Информационный & 20,3 & 27 & 33,8 \\
\hline Организационный & 8,3 & 11 & 13,8 \\
\hline
\end{tabular}

Учитывая некоторую степень стохастичности в принятии решения об участии в молодежных программах, а также изменения в социальной сорере, субъекту управления в процессе планирования и оценивания результатов следует допустить возможное отличие реальных результатов от запланированных. При этом нужно принимать в расчет как уменьшение плановых цифр, так и увеличение выявленных по итогам социологического исследования параметров. В связи с 
этим в таблице 2 приведены максимальное и минимальное значения, установленные на уровне 25 \% от плановых. Наибольшие величины могут определяться как целевой ориентир, а наименьшие - как критические, т. е. такой вариант, в случае недостижения показателей которого требуется пересмотр факторов влияния на социальную активность молодежи или изменение механизма реализации социальной программы.

Таким образом, мы представили систему планирования социальной программы в сфере молодежной политики, учет которой позволит оптимизировать ее реализацию.

\section{Ссылки:}

1. Баскакова Д.Ю., Зотов В.В. Механизм реализации социального программирования // Государство и общество: вчера, сегодня, завтра. Сер.: Социология. 2015. № 15 (1). С. 26-34 ; Тощенко Ж.Т. Программирование как инструмент решения социальной проблемы // Социальная политика и социология. 2010. № 5 (59). С. 8-13 ; Челышов С.Ю., 3отов В.В. Повышение эффрективности программно-целевого управления на региональном уровне // Там же. 2016. № 1 (16). C. 80-86.

2. Тощенко Ж.Т. Указ. соч. С. 10-13.

3. Саати Т., Керне К. Аналитическое планирование. Организация систем : пер. с англ. М., 1991. 224 с.

4. Богдан Н.Н., Климова Т.В. Управление социальным развитием организации : учебное пособие. Новосибирск, 2007. 204 с.

5. Данакин Н.С. Социальная технология как способ оптимизации целевого управления в муниципальной сфере // Среднерусский вестник общественных наук. 2013. № 4. С. 46-55.

\section{References:}

Baskakova, DYu \& Zotov, VV 2015, 'The mechanism for implementing social programming', Gosudarstvo i obshchestvo: vchera, segodnya, zavtra. Ser.: Sotsiologiya, no. 15 (1), pp. 26-34, (in Russian).

Bogdan, NN \& Klimova, TV 2007, Management of the social development of organizations, study guide, Novosibirsk, 204 p., (in Russian).

Chelyshov, SYu \& Zotov, VV 2016, 'The efficiency increase of the program and target management at the regional level', Sotsial'naya politika i sotsiologiya, no. 1 (16), pp. 80-86, (in Russian).

Danakin, NS 2013, 'Social technology as a way of optimization of target management in municipal sphere', Srednerusskiy vestnik obshchestvennykh nauk, no. 4, pp. 46-55, (in Russian).

Saaty, T \& Kearns, K 1991, Analytical planning. The organization of systems, Moscow, 224 p., (in Russian).

Toshchenko, ZhT 2010, 'Programming as an instrument for solving social problems', Sotsial'naya politika i sotsiologiya, no. 5 (59), pp. 8-13, (in Russian). 